\title{
Unveiling post-traumatic stress disorder: a literature review
}

\author{
Amanda de Oliveira Santos ${ }^{1 *}$; Ariel Luz Ferreira Soares ${ }^{2}$; Halison Diego Tavares da Silva ${ }^{3}$; Jamesson \\ Silva dos Santos ${ }^{4}$; Lucas Gabriell Pereira da Silva ${ }^{5}$; Welleson Henrike Ferreira da Silva ${ }^{6}$; Pierre \\ Teodosio Felix ${ }^{7}$
}

1-6 Psychology Students at University Center of Vitória de Santo Antão (UNIVISA), Vitória de Santo Antão, Pernambuco, Brazil

7 Professor of Psychology Course at University Center of Vitória de Santo Antão (UNIVISA), Vitória de Santo Antão, Pernambuco, Brazil

E-mail adresses: amandasantospsi21@gmail.com (Amanda de Oliveira Santos), ariel.202118014@univisa.edu.br (Ariel Luz Ferreira Soares), halisondiego@gmail.com (Halison Diego Tavares da Silva), jamessonsantos867@gmail.com (Jamesson Silva dos Santos), lucaassgabii@gmail.com (Lucas Gabriell Pereira da Silva), wellesonferreira@hotmail.com (Welleson Henrike Ferreira da Silva), pierrefelix@univisa.edu.br (Pierre Teodosio Felix)

*Corresponding author

\section{To cite this article:}

Santos, A.O.; Soares, A.L.F.; Silva, H.D.T.; Santos, J.S.; Silva, L.G.P.; Silva, W.H.F.; Felix, P.T. Unveiling post-traumatic stress disorder: a literature review. International Journal of Sciences. Vol. 2, No. 3, 2021, pp.91-93. ISSN 2763-5392.

Received: 10 25, 2021; Accepted: 10 25, 2021; Published: 11 03, 2021

\begin{abstract}
This disorder affects approximately $15 \%$ to $20 \%$ of people who have experienced traumatic events. So to say, it is a predominant disease that is worthy of importance. Posttraumatic stress disorder is an anxiety disorder determined by a series of physical, mental and emotional evidence that can appear up to 6 months after a traumatic event or experience in the patient's life. It usually consists of repeated and irrepressible memories of occurrences for at least 1 month. Tiny or even trivial stimuli can awaken memories that resurface with all the intensity and clarity of the originating event. This memory is usually triggered by stimuli associated with traumatic episode, starting from the most typical to the most common. Therefore, even a considerably safe environment can become dangerous because people can never be sure that they will not feel any stimulus that will cause the unpleasant emotional experience. Symptoms associated with recurrences of trauma are linked to notable restlessness, concussions, and most victims try to avoid this pain and stay away from any stimulus that may provoke the traumatic memory cycle. In this context, in this research, the data were collected from a bibliographic survey of several authors in many databases.
\end{abstract}

Keywords: Post Traumatic Stress Disorder. Disturbance. Trauma.

\section{Introduction}

This article will address the discussion about a particular mental illness, which had already been diagnosed for some time, but has emerged with a constant frequency. PostTraumatic Stress Disorder (PTSD), often and sometimes is always placed in the foreground, due to the traumas and sequelae that arise after a certain factor.

Throughout its physical, emotional and psychic complex, specialists seek to prevent the disease from approaches and interventions. We know of some events throughout history that have been major triggers for this disorder, such as the American Civil War, World War I and World War II, and the Vietnam War. They caused great psychic events in many individuals. These facts caught the attention of the New
England Journal of Medicine, which published in 2002, an issue focused on the relevance of this subject. We can also bring an account of an article already published from the Bachelor of Nursing course of the Integrated Colleges of Ducks (FIP). A student sought a guide for her course completion work, on another theme, However, during the construction of the project the teacher detected some difficulties of concentration in the focus of the research, such as a certain anxiety to perform the same. These behaviors and signs given by the student and noticed by the counselor need to be verified if it was related to the trauma experienced by the student (a tragic traffic accident), in which the teacher had science and followed closely (Ursano, 2002).

Therefore, a question arises, how is the severity of an event being able to interfere in the life and behavior of the 
human being, and may develop a psychological disorder? Victims such as children, adults, the elderly and the various ways an accident can hurt human life, whether fatally, or sequelae in those who manage to survive. With this, we bring an analysis on PTSD - Post-Traumatic Stress Disorder.

\section{Methodology}

This is a data collection study performed from the bibliographic survey. For this survey, articles were retrieved in several databases such as the Paulista Institute of Psychiatry, Brazilian Journal of Psychiatry, Psico-USF and Scientific Electronic Library Online (SciELO). The inclusion criteria determined for the selection of articles were:

- texts available in full, articles Portuguese and English from 2001 to 2019 ;

- master's dissertations and doctoral theses and articles in full that portray posttraumatic stress disorder (PTSD).

All opinions or unreferenced texts served as exclusion criteria in this study.

\section{Results and Discussion}

The present study addresses the historical evolution of the concept of Posttraumatic Stress Disorder (PTSD). Based in France and one of the schools of psychological between trauma and symptoms of hysteria and, in particular, the fundamental work of Charcot and Janet. Freud's contributions are very clear in them, (DSMs) adopt the term PTSD, which evaluates simultaneously (Schestatsky et al., 2003).

Brazilian Psychiatry has begun to recognize the importance of diagnosing posttraumatic stress disorder (PTSD). Although Brazilians have a high prevalence of exposure to traumatic events, such as accidents and homicides, there are few theoretical and empirical studies on PTSD in our country. This article focuses on briefly describing the diagnosis of PTSD, detailing its phenomenology. After discussing the definition of traumatic event, we focused on the challenges of psychic examination of these patients. Next, the description of PTSD symptoms is emphasized, giving clinical examples to illustrate the most important psychopathological concepts. We conclude, emphasizing the importance of the diagnosis of PTSD for Psychiatry, because it provides a reference-conceptual structure for the research of the effects of stress and trauma. (Figueira and Mendlowicz, 2003).

Posttraumatic stress disorder is one of the mental health problems most associated with victimization by violence. It affects everyone by making many suffer daily from it. Research shows that in the United States there are a very large number of soldiers who end up wanting to take their own lives because they can't take it anymore. However, this raises the following question: "Is the treatment being done correctly?". In the case of military personnel suffering from post-traumatic stress disorder, another frequent criticism is that in treatments there is a tendency to medicate patients instead of offering them longer therapies, which require more resources, more time and, with it, more investment. Another cause that may be the reason for these suicides is the abandonment they end up having right after fulfilling their mission. They often end up alone, even in some cases having a good financial income it also takes emotional support (Diez, 2013).

Cognitive Therapy is a focused form of psychotherapy in which the therapist and client work together as a team to identify and solve problems. Therapists help clients overcome difficulties by working with their thoughts, behaviors and emotional reactions. Cognitive therapy has been shown to be effective as an adjunct to medication for severe mental disorders such as bipolar disorder and schizophrenia among other diseases, its efficiency improves greatly over time in addition to improving chronic diseases such as diabetes, cancer, and other diseases. This is already based on several studies. The goal of cognitive therapy is to help individuals achieve remission of their disease and prevent relapse. Much of the work in the sessions involves solving problems in today's life, teaching them to modify their distorted thinking and to adopt a more adapted behavior, where affection can be well elaborated. Therapists program treatment based on a cognitive formulation of mental disorders, that is, through an individualized conception of each patient's cognitive process. This structure is used to understand how life events and experiences led to the development of dysfunctional beliefs, fanciful assumptions and failures in coping strategies (Fontes, 2012).

In Northern Ireland, one study found that the likelihood of people with PTSD developing a suicidal plan is higher than for people without PTSD. This risk is even higher in females $(4.3 \%)$ when compared to males $(2.3 \%)$. In Ribeirão Preto (SP), a sample of pregnant women from the 36th gestational week who suffered IPV was studied. The prevalence of PTSD and suicidal ideation was 17.0 and $7.8 \%$, respectively. Pregnancy possibly explains the disparity in the prevalence of PTSD among the populations of Hawaii and Israel, compared to that of Ribeirão Preto (Neto et al., 2020).

\section{Conclusions}

Post-Traumatic Stress Disorder has affected fathers, mothers, children and families through child abuse, maltreatment, drug addiction, family violence, violence in the workplace. It has caused individuals to feel a sense of threat. It was clear in this review that PTSD has taken people who have historically been exposed to situations of extreme suffering, generating trauma. As PTSD is a chronic problem and can last for a lifetime, most victims try to avoid stimuli that can trigger the cycle of traumatic memories, which reduces symptoms with this treatment. Symptoms can appear at any age range and take months or even years to reveal themselves. It is normal for patients to have comorbidities associated with PTSD (Varella, 2010).

\section{References}


[1] Díez, B. EUA buscam saídas para frear suicídios de soldados. BBC NEWS|BRASIL. 2013. Disponível em:https:/www.bbc.com/portuguese/noticias/2013/06/1 30606_soldados_suicidio_gm acessado em: 05 de outubro de 2021 .

[2] Figueira, I.; Mendlowicz, M. Diagnóstico do transtorno de estresse pós-traumático. Brazilian Journal of Psychiatry. 2003. Disponível em: https://www.scielo.br/j/rbp/a/yhBZ6h6cv6fXpq88GzxV 47q/?lang=pt Acessado em 05 de outubro de 2021.

[3] Fontes, M.A. O que é Terapia Cognitiva? Plenamente. 2012. Disponível em: http://plenamente.com.br/artigo.php?FhIdArtigo=168 Acessado em 18 de outubro de 2021.

[4] Neto, P.J.A.V.; Moreira, R.F.; Júnior, F.J.M.O.; Ludermir, A.B. Tentativa de suicídio, transtorno de estresse póstraumático e fatores associados em mulheres do Recife. Revista Brasileira de Epidemiologia. 2020. Disponível em:

https://www.scielo.br/j/rbepid/a/RLhTKKbDZgWR9Z9 Tgs9Ltgr/?lang=pt Acessado em 18 de outubro de 2021.

[5] Schestatsky, S.; Shansis, F.; Ceitlin, L.H.; Abreu, P.B.S.; Hauck, S. A evolução histórica do conceito de estresse pós-traumático. Brazilian Journal of Psychiatry. 2003. Disponível em: https://www.scielo.br/j/rbp/a/gxnPtSK5x4qBfCtnQ6Sq9 LB/abstract/?lang=pt Acessado em 18 de outubro de 2021.

[6] Ursano, R. J. Transtorno de estresse pós-traumático. The New England Journal of Medicine, 2002. Disponível em: https://www.nejm.org/doi/full/10.1056/nejm200201103 460213 acessado em 05 de outubro de 2021.

[7] Varella, M.H. Transtorno do estresse pós-traumático. Drauzio Varella. 2010. Disponível em: https://drauziovarella.uol.com.br/doencas-esintomas/transtorno-do-estresse-pos-traumatico/ acessado em 18 de outubro de 2021. 